\section{Bilateral Ptosis and Limb Myokymia: Regional Variant of Guillain-Barré Syndrome?}

Felix Cheng'1, MD, Jonathan S. Katz, MD², Richard J. Barohn, $\mathrm{MD}^{3}$, and Gil I. Wolfe, MD ${ }^{1}$

${ }^{1}$ Department of Neurology, Jacobs School of Medicine and Biomedical Sciences, University at Buffalo/SUNY, Buffalo, NY

${ }^{2}$ Department of Neurology, California Pacific Medical Center, San Francisco, CA

${ }^{3}$ Department of Neurology, University of Missouri School of Medicine, Columbia, MO

Keywords: Guillain-Barré syndrome, ptosis, antiganglioside antibodies, myokymia.

\section{Introduction}

Guillain-Barré syndrome (GBS) typically presents with distal paresthesias, ascending paralysis, and areflexia. Several variants have been described, most notably the Miller-Fisher syndrome (MFS) which accounts for about $5 \%$ of all GBS cases., ${ }^{1,2}$ Less common regional variants include pharyngeal-cervical-brachial (PCB) weakness, paraparesis, facial diplegia with distal paresthesias, and severe ptosis without ophthalmoplegia. ${ }^{3,4}$ Ptosis without ophthalmoplegia occurs in approximately $8 \%$ of patients with typical GBS but is also seen in regional forms, particularly the PCB variant. ${ }^{3,5}$ Isolated bilateral ptosis as an initial sign of GBS with subsequent limb paralysis or paresis has been reported. ${ }^{3,-7}$ However, bilateral ptosis with subsequent limb myokymia but without ophthalmoplegia, facial or extremity weakness has not been reported in the literature to our knowledge.

We describe a patient who developed severe bilateral ptosis over several days. There was no facial or extremity weakness although he did have limb myokymia. Laboratory studies excluded common causes of ptosis and were suggestive of GBS. We believe our patient extends the clinical spectrum of GBS, and that binocular ptosis represents a mild regional variant of this neuropathy.

\section{Case Report}

A 44-year-old man developed drooping of both upper eyelids following a full day of fishing. Over one week the ptosis progressed to the point that he had to hold up his eyelids in order to see. He also noticed tingling in his extremities, mild difficulty swallowing, and involuntary movement in his left forearm and hand. He denied limb weakness, blurry or double vision, nausea or vomiting, diarrhea, constipation, and bladder involvement. There was no antecedent illness, and no other family members were ill.

Neurologic examination one week after onset showed bilateral symmetrical ptosis with full extraocular movements that persisted four months after onset (Figure la). Otherwise, cranial nerves, strength, sensation, and deep tendon reflexes were normal. In addition, there was a visible undulation in the left first dorsal interosseous muscle causing abduction-adduction movements of the index finger. Involuntary movements of his forearm had resolved three months earlier. Neurologic examination was otherwise normal.

Edrophonium testing was negative. Head magnetic resonance imaging, acetylcholine receptor antibodies, Lyme titers, thyroid function tests, serum lactate, and cre-

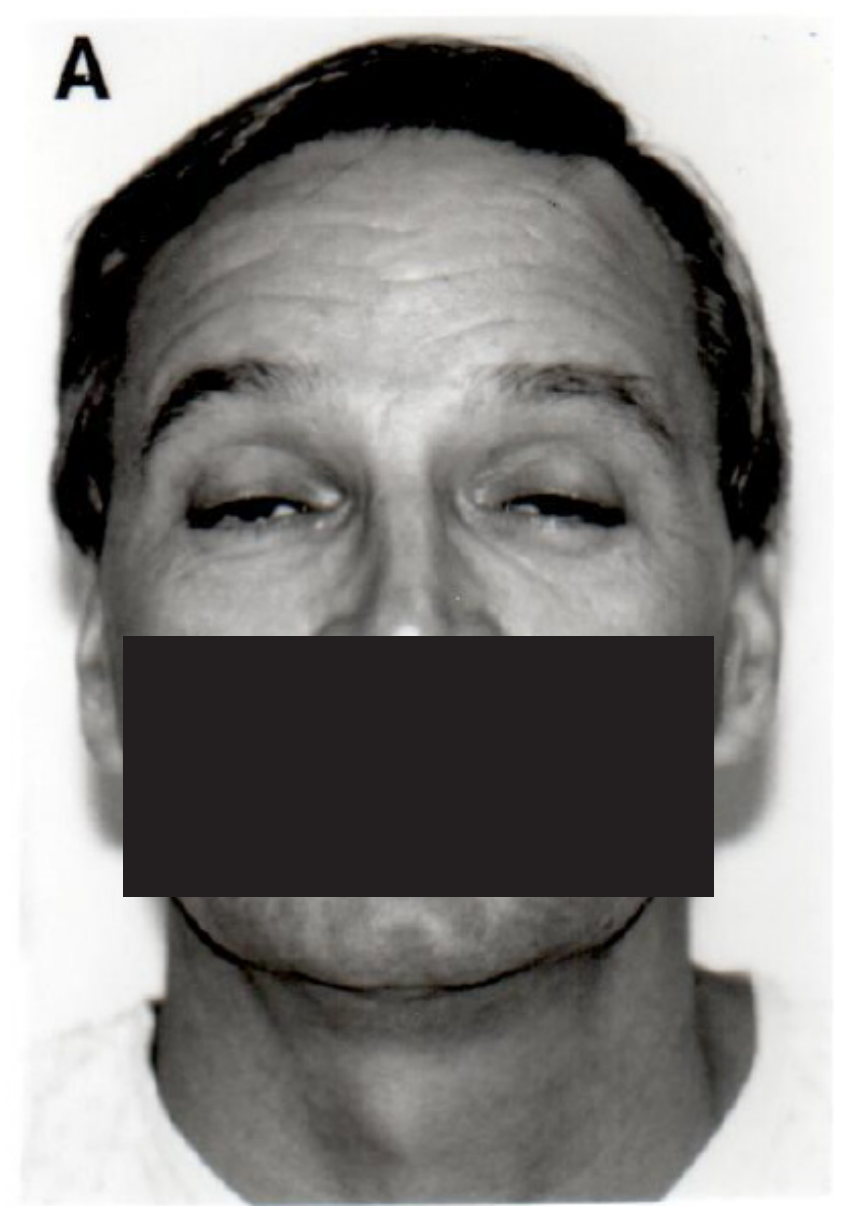

Figure la. Photograph of patient demonstrating symmetric ptosis four months after onset. 
atine kinase were normal. CSF evaluation seven days after the onset of symptoms showed $1 \mathrm{WBC} / \mathrm{mm} 3$ and protein of $71 \mathrm{mg} / \mathrm{dl}$ (normal 15-50 mg/dl). Nerve conduction studies including repetitive stimulation were normal. IgM GMl antibodies $(47.0 \mathrm{mg} / \mathrm{mL}$, high titer $>22.0 \mathrm{mg} / \mathrm{mL}$ ), IgM asialo GMlantibodies $(63.7 \mathrm{mg} / \mathrm{mL}$, high titer $>22.0 \mathrm{mg} / \mathrm{mL})$, and IgG asialo-GMl antibodies (4.6mg/mL, high titer $>4.5 \mathrm{mg} /$ $\mathrm{mL}$ ) were elevated (Associated Regional and University Pathologists, Salt Lake City, UT). IgG GMl antibody was not detected.

Lumbar puncture four months after onset showed a CSF protein of $54 \mathrm{mg} / \mathrm{dl}$. Antiganglioside antibodies were no longer elevated. Antibodies to GQ1b were negative (Athena Diagnositics, Worcester, MA). Nerve conduction studies and $\mathrm{F}$ responses of the right median, ulnar and peroneal nerves, as well as 3 and $50 \mathrm{~Hz}$ repetitive stimulation of the left ulnar nerve and $3 \mathrm{~Hz}$ repetitive stimulation of the facial nerve, were normal. Electromyography (EMG) demonstrated a myokymic discharge in the left first dorsal interosseous muscle with a frequency of $2.7 \mathrm{~Hz}$ and 3-5 motor units per discharge (Figure lb). Large amplitude motor units and mildly reduced recruitment were localized to distal arm muscles.

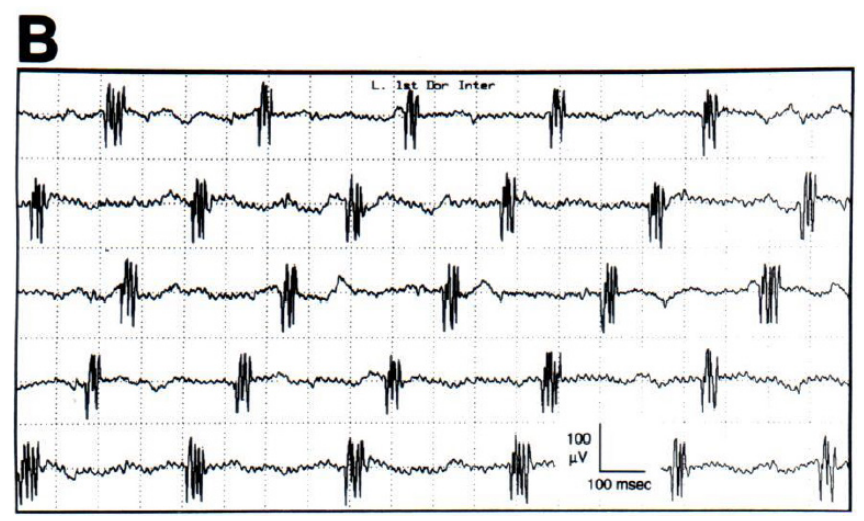

Figure 1b. Myokymic discharge with a frequency of $2.7 \mathrm{~Hz}$ recorded from the left first dorsal interosseous muscle.

Pyridostigmine bromide provided no benefit. The paresthesias and swallowing difficulty resolved after two months. The ptosis and myokymia began to improve after five months with further resolution at 8 months after onset.

\section{Discussion}

Our patient's subacute progression, slow improvement over months, elevated CSF protein, and myokymia led us to a diagnosis of GBS. Laboratory and radiologic studies excluded other causes of bilateral ptosis including myasthenia gravis and intracranial lesions. Botulism and diphtheria were not serious diagnostic considerations in a setting of elevated CSF protein, normal nerve conduction studies and repetitive stimulation, and absent visual and gastrointestinal symptoms. ${ }^{3,5}$ There was no evidence of myopathy.

Ptosis without ophthalmoplegia is a recognized feature of GBS and is seen in the PCB variant. The eyelid drooping and mild swallowing difficulty in our patient are suggestive of the PCB variant which resembles botulism and is characterized by ptosis, severe dysphagia, shoulder girdle weakness, and respiratory failure. ${ }^{3}$ Ropper popularized the concept of regional variants in GBS. These variants include "abortive forms" that maintain an atypical pattern throughout the illness and "transitional forms" which begin with a regional pattern and evolve into the more typical syndrome. ${ }^{3}$ We believe our patient's illness represents a mild "abortive form" of GBS.

Myokymia and grouped repetitive discharges on EMG are important indicators of demyelinating disorders, ${ }^{8-9}$ and in one series were present in $17 \%$ of patients with GBS. ${ }^{10}$ Myokymia appears early in the course of GBS, usually involving facial muscles and lasting two to three weeks. ${ }^{10}$ However, limb myokymia also occurs and may persist for several months. ${ }^{10,11}$ Other causes of limb myokymia include radiation injury, direct toxic effects, ischemia, and nerve compression, none of which were serious diagnostic considerations in our patient.

Our patient had normal reflexes and muscle strength. Motor weakness and reduced tendon reflexes are key diagnostic criteria for classic forms of GBS. ${ }^{12}$ Clinical criteria for regional variants have also included hyporeflexia or areflexia. ${ }^{5}$ However, reflexes are preserved in a small percentage of patients with typical GBS and may be spared in unaffected limbs in regional variants. ${ }^{3,13}$ For instance, reflexes are preserved in the legs of patients with the PCB variant ${ }^{3}$ and in mild cases of MFS. ${ }^{14-15}$ Patients with a GBS variant characterized by facial diplegia and paresthesias may have normal reflexes in early stages and may only lose their ankle jerks. ${ }^{16}$ It is possible our patient developed hyporeflexia between office visits, but it was never documented.

The search for an antigen target in GBS has been inconclusive. IgG antibodies to the ganglioside GQlb are elevated in MFS patients, ${ }^{17}$ and a large proportion of GBS patients demonstrate antibodies to one or more gangliosides, including GMl and asialo- GM1. ${ }^{18-21}$ Our patient initially had high titers of IgM and IgG antiganglioside antibodies which were no longer detected at four months. This time course is in accord with anti-acidic glycolipid antibody titers measured longitudinally in GBS patients ${ }^{19}$ and serial anti-GM1 
titers from patients who developed an axonal form of GBS following parenteral ganglioside injections. ${ }^{18}$ Still, many GBS patients do not have elevated antiganglioside antibodies, raising considerable uncertainty about a pathophysiologic role for these circulating factors.

In conclusion, we believe our patient had a mild, abortive form of GBS. Regional presentations of GBS may result from an immunologic response localized in distribution or limited in intensity and from antigenic differences among peripheral nerve populations. Our patient demonstrates that GBS may present in a highly localized manner and underscores the difficulty in setting clinical limits on this syndrome.

Corresponding author: Gil I. Wolfe, MD, Department of Neurology, University at Buffalo, 1010 Main Street., Buffalo, NY 14202.

\section{References}

1 Govoni V, Granieri E: Epidemiology of the GuillainBarré syndrome. Curr Opin Neurol 2001;14:605-613.

2 Hughes RA, Cornblath DR: Guillain-Barré syndrome. Lancet 2005;366:1653-1666.

${ }^{3}$ Ropper AH: Unusual clinical variants and signs in Guillain-Barré syndrome. Arch Neurol 1986;43:1150-1152.

${ }^{4}$ Govoni V, Granieri E, Tola MR, Casetta I, Ruppi P, Vaghi L: The frequency of clinical variants of Guillain-Barré syndrome in Ferrara, Italy. J Neurol 1999;246:1010-1014.

${ }^{5}$ Ropper AH, Wijdicks EFM, Truax BT: Guillain-Barré Syndrome. Philadelphia, FA Davis, 1991: pp 18-225.

6 Teng HW, Sung JY. Ptosis as the initial presentation of Guillain-Barré syndrome. J Emerg Med. 2012;43:e2835.

7 Talebian A, Soltani B, Talebian M. Bilateral ptosis as the first presentation of Guillain-Barré syndrome. Iran J Child Neurol. 2016;10:70-72.

8 Gutmann L: AAEM minimonograph \#37: facial and limb myokymia. Muscle Nerve 1991;14:1043-1049.

9 Roth G, Magistris MR: Neuropathies with prolonged conduction block, single and grouped fasciculations, localized limb myokymia. Electroenceph Clin Neurophysiol 1987;67:428-438.

${ }^{10}$ Mateer JE, Gutmann L, McComas CF: Myokymia in Guillain-Barré syndrome. Neurology 1983;33:374-376.

${ }^{11}$ Albers JW, Allen AA, Bastron JA, Daube JR: Limb myokymia. Muscle Nerve 1981;4:494-504.
${ }^{12}$ Hughes RA, Rees JH: Clinical and epidemiologic features of Guillain-Barré syndrome. J Infect Dis 1997;176:9298.

${ }^{13}$ Parry GJ: Guillain-Barré Syndrome.New York, Thieme Medical Publishers, 1993. pp 10-32.

${ }^{14}$ Yuki N, Odaka M, Hirata K. Acute ophthalmoparesis (without ataxia) associated with anti-GQlb IgG antibody: clinical features. Ophthalmology 2001;108:196-200

${ }^{15}$ Lee SH, Lim GH, Kim JS, et al. Acute ophthalmoplegia (without ataxia) associated with anti-GQlb antibody. Neurology 2008;71:426-9.

${ }^{16}$ Ropper AH: Further regional variants of acute immune polyneuropathy. Arch Neurol 1994;51:671-675.

${ }^{17}$ Chiba A, Kusunoki S, Obata H, Machinami R, Kanazawa I: Serum anti-GQlb IgG antibody is associated with ophthalmoplegia in Miller Fisher syndrome and Guillain-Barré syndrome: clinical and immunohistochemical studies. Neurology 1993;43:1911- 1917.

${ }^{18}$ Illa I, Ortiz N, Gallard E, Juarez C, Grau JM, Dalakas MC: Acute axonal Guillain-Barré syndrome with IgG antibodies against motor axons following parenteral gangliosides. Ann Neurol 1995;38:218-224.

${ }^{19}$ Ilyas AA, Mithen FA, Dalakas MC, Chen Z, Cook SD: Antibodies to acidic glycolipids in Guillain-Barré syndrome and chronic inflammatory demyelinating polyneuropathy. $\mathrm{J}$ Neurol Sci 1992;107:111-121.

${ }^{20}$ Nobile-Orazio E, Carpo M, Meucci N, et al: GuillainBarré syndrome associated with high titers of anti-GMl antibodies. J Neurol Sci 1992;109:200-206.

${ }^{21}$ Rees JH, Gregson NA, Hughes RAC: Anti-ganglioside GMl antibodies in Guillain-Barré syndrome and their relationship to Campylobacter jejuni infection. Ann Neurol 1995;38:809-816. 